\title{
Using a Shared Workspace and Wireless Laptops to improve Collaborative Project Learning in an Engineering Design Class
}

\author{
David J. Nicol ${ }^{\mathrm{a}, *} \&$ Iain A. MacLeod ${ }^{\mathrm{b}}$ \\ ${ }^{a}$ Centre for Academic Practice, University of Strathclyde, Scotland, UK \\ ${ }^{b}$ Department of Civil Engineering, University of Strathclyde, Scotland, UK
}

\begin{abstract}
Two different technologies, groupware (a shared workspace) and shared wireless laptop computers, were implemented in a project design class in a civil engineering course. The research interest was in the way these technologies supported resource sharing within and across project groups and in the forms of group collaboration that resulted. The initiative was evaluated using both qualitative (e.g. pyramid discussion) and quantitative methods (e.g. survey, logs of usage). The results showed that these technologies helped improve group sharing of resources and supported different kinds of group collaboration. The shared workspace provided a location-independent central repository of resources around which group activities were coordinated whereas the laptops provided a focal point for the face-to-face discussion of these resources. The paper discusses the importance of embedding supportive technologies and the different forms of learner collaboration mediated by each technology.
\end{abstract}

Keywords: Collaborative learning, Distributed learning environments, Teaching/learning strategies, Pedagogical issues, Post-secondary education.

\section{Introduction}

Across most disciplines in higher education there has been a growing interest in collaborative learning using group projects. Group projects normally involve students working together over a period of time in order to complete a complex and openended task. This requires that members of the group plan, negotiate and co-ordinate their activities and share information and resources. Research has shown that such collaborative activities can be beneficial to individual learning (Cohen, 1994, Slavin, 1994; Quin, Johnson \& Johnson, 1995; Johnson, Johnson \& Smith, 1998; deCorte, 1998) although it has also been shown that these benefits are dependent on both the quality of the learner interaction and on the attitudes of students to group collaboration (Walker, 2001, Underwood, 2003).

In recent years, computer-based systems have been harnessed to support collaborative learning in higher education. In 1996, Koschmann identified 'computer supported

\footnotetext{
* Corresponding author. Tel: +141 548 4060; fax +141 5532053

E-mail address: d.j.nicol@strath.ac.uk (D.J.Nicol)
} 
collaborative learning' (CSCL) as an emerging paradigm in learning research (Koshman, 1966). CSCL is based on the premise that computer tools alter the social arrangements amongst learners and result in new kinds of peer interaction and joint activities (Dillenbourg, 1999). Research on CSCL focuses on how computer applications might be used to scaffold knowledge building and knowledge sharing amongst members of a group (Crook, 1994; Roschelle \& Teasley, 1995).

There is also research interest in the different ways that computer technologies might mediate and support collaborative learning. For example, Crook (1994) has proposed four types of collaborative interactions in which computers play a part; interactions at computers, around computers, related to computers and through computers. Each of these interaction patterns can be shown to mediate different group learning processes. More recently, Oliver and McLouglin (2001) have shown how different web tools can be used to support different group kinds of group activities including online debates, the sharing of problems and solutions and task-related communication. Other researchers have investigated how the same tool might support different types of collaborative activity. Of particular relevance here is a study by Sikkel, Gommer \& van der Veen (2002) that evaluated seven higher education courses where students used online groupware technology for a variety of different collaborative purposes (e.g. archiving resources, collaborative authoring, online discussions). They concluded that the main strength of groupware was as 'a repository for the objects of collaborative work'. Research suggests that shared access to such task-relevant resources is a key factor in successful group working (Shaikh and Macauley, 2001).

The study reported in this paper extends this body of research by investigating how the application of two different computer technologies - groupware and shared laptops with wireless access - might be used to support resource sharing and group collaboration in a Civil Engineering project design class in higher education. The paper begins with an explanation of why the department decided to introduce these supportive-technologies into the project design class.

\section{Concerns about group project learning}

\subsection{Background to the Project Class}

In the third year of the undergraduate degree course in Civil Engineering at the University of Strathclyde all students are required to take a core class entitled 'Civil Engineering Projects 3'. This design project class lasts for one semester (12 weeks) and involves group collaboration in relation to a 'realistic' industrial project. The project brief is the re-development and planning of an industrial site and the design of facilities for the site. Group working in this class is compulsory and is seen as a necessary preparation for professional practice.

The project has three distinct but overlapping stages. First, the students in groups of six visit the site and gather relevant information and resources. Secondly, the groups evaluate proposals for the use of the site, summarise the technical issues and produce a development planning report. In stage three, the groups engage in further research and produce a design report for the redevelopment of the site. Each of these three stages is designed around a reflective cycle (see Cowan, 1998) that involves planning, acting, and reflection on group progress. 
Although all project groups are working on the same redevelopment problem the open-ended nature of the project means that each group generates its own development planning report and design solution. As a result, some task resources are common to all project groups (e.g. technical reports, site drawings, references to literature, design guidance, codes of practice) while other resources are specific to a project group (e.g. draft reports, photographs). Hence, collaboration and information sharing are necessary both within and across project groups.

To facilitate sharing of resources across project groups and to avoid duplication of research effort a management group is formed comprising one representative from each of the project groups. This group normally meets once a week with the course director. One key role of the representative is to take resources back to their project groups after the management group meetings and to inform their project group about where relevant information is located.

\subsection{Group projects issues}

In running this design project over a number of years, some recurrent issues had emerged. Firstly, it was found that information and resources were not always shared effectively amongst members within the small project groups. The project was large and complex and the resources were extensive (technical reports, drawings, images, guidance etc.) and therefore students found it difficult to organise them for sharing. Also, at times, students might not be able to attend the face-to-face meeting with members of their project group with the result that at group meetings some resources might not be available for discussion. Secondly, the management group was not completely effective as a means of sharing information and resources across the class (across all project groups). Sometimes the management group representative did not attend meetings and/or report back fully to their project group. Also it was expensive and time-consuming to photocopy resources for all project groups (e.g. large files, site plans); and if copies of resources were housed in the library or department it could still be difficult for students to get access when needed.

These concerns - poor sharing of information resources within and across project groups - led the course director to search for better ways of supporting group project work in engineering design.

\section{Supporting resource sharing and group collaboration}

Two technologies were introduced to support group project work in the engineering design course - web-based groupware technology and shared portable laptops with wireless networking.

Groupware supports collaborative learning by providing a web location for the storage and management for shared resources. When used in the context of group projects, groupware acts as a 'shared workspace' - a central access point and repository for working documents that can be updated, and added to, by group members at anytime and from any web address. 
Wireless laptops make it easy for students to access remote resources at any location within the vicinity of a base station. A pilot investigations in our own institution in a business module had shown that being able to sit down as a group and access resources by wireless laptop can support group discussions of those resources. However, in that investigation, the number of laptops matched the number of students making it expensive to implement. In this study, we were interested in exploring whether there would be benefits if laptops were shared amongst members of a project group (i.e. one laptop per group of six students).

The main objectives of this study were therefore (1) to ascertain whether these two technologies (laptops and a shared workspace) might help address the concerns raised by academic staff - poor sharing of resources within and between project groups, and (2) to explore the different ways that each of these two technologies might mediate and support collaborative working in groups (Crook, 1994; Oliver and McLouglin, 2001). Unlike previous research, this study compares the effects of these technologies on resource sharing and collaboration in the same educational context. It also provides some evidence on the value of shared wireless laptops in collaborative learning contexts. There is an absence of published research on laptop use in higher education.

\section{Implementation of the Project Design Class}

In this paper we report on the implementation in 2001-2 of these two technologies in the Engineering Design project class. In that year, the project involved the redevelopment of a nineteenth century harbour. In the course documentation, the expected learning outcomes were to develop students' ability to:

- assess re-development options

- carry out the design of a civil engineering works

- collaborate as a member of a team

- locate and share information and resources

- communicate in writing, graphics and through oral presentations

There were 36 students in the project class in 2001-2 divided into six groups of six students with one female group and the rest male. Ages were between 19-24 years.

\subsection{The Technologies}

The technologies used to support this class were IBM laptops and a groupware technology called BSCW (Basic Support for Cooperative Work). The laptops were provided with radio frequency communication cards and there were base stations (receivers) in the design studio and in other locations across the university. A comprehensive software image was mounted on each laptop prior to distribution. No special instructions were given about how to share or use the laptop.

The BSCW software, marketed by Orbi, GMD, was established on a departmental server. BSCW could be accessed from any internet address using a web browser. Resources in BSCW are organised in folders and subfolders and links can be made to resources on other websites. Access rights to folder can be designated using a simple username and password scheme. 


\subsection{Project and Management Group Folders}

A folder was set up on BSCW for each project group. Members of each project group were then free to structure their own sub-folders in their own way. Only group members plus the course director had access rights to the each group folder (i.e. members of one group could not access another group's folder).

A management group folder was also set up on BSCW. The course director prescribed the structure for this. The designated sub-folders were:

- Project Management: for minutes of meetings, course documentation and requirements etc.

- Context: information specific to the site such as drawings, technical reports etc. This information was generated mainly from documents derived from external sources.

- References: the groups were required to post in this folder references to information relevant to the project obtained from sources such as library searches, web searches, tutors, suppliers, etc.

All students in the class had access to the management group folders. When the management group met with the course director to discuss the project, decisions were made about what resources would be uploaded to the management group folders. Files might be moved from a group folder to the management group folder or the management group might search for and then post new resources if gaps were discerned in relation to the project brief.

\subsection{Assessment}

The assessment for this class was divided between a group mark and an individual mark. The group work is worth $50 \%$ of the total marks and is based on assessment of the two group reports (development and design reports) and two group presentations. The individual mark is based on an assessment of individual contributions in the design report (separately authored sections) and an assessment made by the course director of each student's individual contribution to the overall group working.

\section{Evaluation Methodology}

The evaluation explored students' perceptions and experiences of using groupware technology and shared laptops for resource sharing and collaborative working. It also examined the actual use of resources in the shared group workspaces. The first author (DJN) carried out the evaluation and analysed the data. Both qualitative and quantitative methods were used to collate student views.

\subsection{Qualitative methods}

There were two sources of qualitative data. Firstly, focus group meetings were held with two project groups in the second week. This was used to gauge initial reactions to the use of the groupware and the shared laptops and to make sure that there were no technical problems with the groupware and laptop technologies. Second, a structured 'pyramid discussion' was held with all those taking part in the project design class in a single two-hour session at mid-semester. With this method, students first write 
down their individual reactions to the project class on a single A4 proforma. This asks them to record (i) the good and (ii) the difficult features of the class and (iii) to propose recommendations to overcome difficulties. Students then share and discuss their written reactions in their groups and compile a written group report using the same headings. In a plenary session, the evaluator goes round the small groups asking them to make public the points recorded in the small group report. He records these points on a flip chart and facilitates an open discussion around each point with the whole class. He then publicly summarises to the class how he might record the class views including the areas of consensus and disagreement. This pyramid discussion provides a rich source of data at three levels - individual reports, group reports and the plenary framework with the different views across the class recorded.

\subsection{Quantitative methods}

The main quantitative method was an end of the semester survey that comprised 28 statements. A $100 \%$ response rate was achieved. The statements were derived from the focus group and the pyramid discussion data. Issues raised in these discussions were analysed, interpreted and categorised by the evaluator. The most frequently reported issues were then re-formulated into single sentence statements and linked to a five-point Likert scale. The range descriptors were from 'strongly agree' to 'strongly disagree'. The intention was to quantify the views initially derived from the focus group and pyramid discussion. While most statements were phrased in the positive some were phrased in the negative to discourage rote responses. Some survey items were also designed to allow cross-checking for consistency and a few key survey statements had space to give a reason for an answer.

\subsection{Use of the shared workspace}

As well as data on students' experiences it was possible to examine the shared repository to evaluate the extent of its usage from automatic login data and the way students had organised their resources in sub-folders within the project group folders and within the management group folders. Automatic Login data also provides information about from where (e.g. within or outside university), when (day or night).and with what (laptop or other computer) students access the shared workspace.

\subsection{Comparative data from a fourth year project class}

All of the above refer to the evaluation of the third year Civil Engineering project class. Over the same time period, a fourth year project class was also in progress with similar goals, focus, format and assessment procedures. In this class students were given access to a groupware to create a shared workspace but were not given wireless laptops. Evaluations of this class allowed us to clarify some interpretations of the third year data.

\section{Results}

The results are presented in three sections. This first section reports on the extent to which the shared workspace helped support resource sharing and collaboration within project groups. The next section reports on the value of the shared workspace in 
supporting resource sharing and collaboration across project groups. The third section reports on the role of the laptops in supporting resource sharing and collaboration.

The results comprise both qualitative and quantitative data about students' perceptions of collaborative learning using these technologies (see above). The quotes in the text below present a qualitative account of students' experiences. These are drawn from mainly from the pyramid discussions but also, where relevant, from the focus group meetings and from the written responses to survey statements. These quotes are linked in the text to the quantitative data from the survey. Each set of data, qualitative and quantitative, complements the other. The survey results have been organised into three tables (Tables 1, 3 and 4) and referenced to the three sections. When referring to these three tables in the text that follows [T1:S1], for example, would refer to Table 1, survey statement 1 . Other quantitative data presented refers to the usage and organisational structure of resources in the shared repository.

\subsection{The shared workspace and resource sharing and collaboration within project groups}

Table 1 provides the survey data relevant to this section. In the pyramid discussions and in the survey (T1:S1), the majority of students agreed that the BSCW website helped support team working in the engineering project class.

\section{[TABLE 1 ABOUT HERE]}

When asked 'how does BSCW support team working' the main reason given was that the repository made it easy for the project group to share and access project resources. Typical comments were:

With BSCW you can upload information to the project group site from any location and you can update existing files or add new files if you find something useful. Access from home is helpful.

Information can be accessed from anywhere. This is good when students have different timetables. With all the information posted on the website you don't have to run around collecting bits of paper nor do you have problems with someone hoarding a document.

These comments were confirmed by the survey with almost all students agreeing that 'the BSCW website helps students to share project resources' (T1:S2). Students also reported that the sharing of documents using the BSCW workspace was more effective than sharing by e-mail, and this was confirmed in the survey (T1:S3). For example:

In the past we emailed documents to each other. This created problems with lost files and people saying they didn't get the file. With the group folder you can post something and you know it is there and everyone has access.

Another reported benefit of the shared workspace was the opportunity it afforded to assess current progress of the group (T1:S4). An examination of documents and draft 
reports posted in the project group folders on the BSCW site gave students 'a good picture of group progress'. The course director also reported that the project folders made it much easier than in the past to keep track of each group's progress. Many students also reported that they derived satisfaction from seeing resources that they had retrieved being posted on the project group website. This motivational effect was confirmed in the end of semester survey (T1:S5).

Although the shared workspace had positive benefits in terms of supporting collaboration and resource sharing within project groups students were divided (or neutral) about whether the shared workspace helped improve communication within their project groups (T1:S6). Arguably this was because students had ample opportunity to meet face-to-face in this project.

The Organisation of the Data Repository. Despite the generally positive comments about BSCW as a repository for sharing resources, some students expressed concerns about how resources were organised in the repository. Most agreed that to make maximum use of project resources a good structure for the project folders was essential.

$B S C W$ is good but a better hierarchy of files is needed for the group folders to make access to information easy and sharing more effective.

This point was confirmed in the survey (T1:S7). In addition, an analysis of project group folders on the BSCW site reveals that there were differences across project groups both in the quantity of project resources uploaded and in their organisation. Table 2 shows that the number of files uploaded ranged from 4 to 50 and the number of nested sub-folders below root ranged from 0 to 2 . The latter is a measure of the extent of the hierarchy.

\section{[TABLE 2 ABOUT HERE]}

However, there were different views amongst students about who should define the structure for the project group folders. A majority (59\%), but not all, of the students maintained that the teacher should define a structure for the project group folders as was done with the management group folders (T1:S8). Another improvement suggested by students in the pyramid discussion and given some confirmation in the survey data was the idea that resources uploaded to the shared workspace should be given a 'usefulness rating' (T1:S9). This would provide a guide to other students about the potential value of a resource. A facility for this was available within BSCW but was little used by the students.

Practical Considerations. Most students (85\%) reported that the BSCW facility was easy to use (T1:S10) although around 50\% still reported that they would have liked more guidance (T1:S11). The main difficulties reported were the slow access time for large documents from outside the university, some navigation difficulties related to the poor structure of sub-folders (see above) and problems in uploading images to the site. These difficulties may account for the fact that only $53 \%$ of the students agreed that their project group had taken full advantage of the BSCW facilities (T1:S12). 


\subsection{The shared workspace and resource sharing and collaboration across project groups}

Table 3 provides the survey data relevant to this section. In the survey, the majority of students agreed that 'the sharing of resources from the project group to the management group [had] worked well in this project class' (T3, S1). In the pyramid discussions and in the written responses to the survey questions, students reported that the value of the management group folders was that (i) they facilitated the sharing of general resources across all project groups (ii) that 'sometimes you learn about the working methods of other groups' through the resources they uploaded to the management folders and (iii) that you 'didn't have to ask your group representative for information about what happened in the management group meetings because you could read it from the BSCW site'.

\section{[TABLE 3 ABOUT HERE]}

Although most students expressed support for the idea of a management group both to facilitate the sharing of resources and to support communication across project groups (T3:S2) a small number of students (T3:S1, 18\%) reported that the management group folders had not worked well in the project. The main concern expressed by these students was not about the value of the management group folders per se but was about the idea of sharing resources across the project groups. In the pyramid discussions many students maintained that if project groups posted their resources onto the management group workspace there was a danger that other groups would 'steal' their ideas.

Other groups who did not put in time and effort could unfairly copy the work of others.

The group folder privacy helps prevent copying of unique or innovative ideas.

The survey data also reinforced this point with over $50 \%$ of students opposing the idea that all areas of the shared workspace (i.e. all project group folders) should have unrestricted access (T3:S3). Further questioning during the pyramid discussions revealed that, at least in part, the students' concern about sharing was linked to the fact that they were not convinced that the work of their project group would be judged on its own merit in the assessment process (criterion referenced). Instead, they believed that the project group marks would be based on a relative assessment of performance across the groups (norm referenced). This was in spite of the fact that the course documentation, and the course director, had emphasised that assessment would be criterion referenced and that sharing was a key objective of this project. One way to resolve this problem might be to assess the level of contributions made by the project groups to the management group folder. However, in the survey (T3:S4) there were mixed reactions to this idea ( $26 \%$ agreed: $47 \%$ disagreed).

In the survey, and in discussions, there was also some evidence that students considered the project group folders to be more valuable to project work than the management group folders (T3:S5, T3:S6) although the differences are small. 
Arguably, this finding is further evidence that students are more favourable to resource sharing within rather than across project groups.

Pattern of access to shared workspace. Figure 1 shows total student access to the shared workspace (both the project and management group folders) over the time course of the module for both third and the fourth year students who were doing a similar module. Two features should be noted. Firstly, in both years, the access patterns follow the activity patterns of the module with the peaks occurring when there was an assessment demand (e.g. interim/final reports or a presentation of work). Second, the fourth year students evinced a higher overall usage of the shared workspace than the third year students. One possible reason for this is that the third year students used their laptops to store some shared documents rather than upload them to the shared workspace. There was some anecdotal evidence in students' comments to support this but we were unable to ascertain the extent of this kind of usage.

\section{[FIGURE 1 ABOUT HERE]}

In conclusion, despite some difficulties in managing resources, most students maintained that the shared workspace was a success. Indeed, in the survey, the majority (85\%) reported that a web-based facility like BSCW should be made available to all university students to support their study (T3:S7).

\subsection{Laptops and resource sharing and group collaboration}

As with the shared workspace students were divided (or neutral) about whether the laptops helped improve communication within their project groups (T4:S1). According to the students, the main value of the wireless laptop was that it 'provided a focal point' for collaborative study around project resources (T4:S2). Members of the project group could sit at a table around the computer, in any location in the department where there was free space, and discuss their project work, access documents from the shared workspace, write reports together and update the files in the repository. Typical comments in the pyramid discussions were:

The wireless laptop was very useful as it meant that if we were discussing the project around a table the laptop could be produced and the documents accessed without us having to leave the room to get a computer. This saved time and encouraged us to work together. Also it helped us write reports together.

As well as viewing documents on the laptop screen some students also shared their documents using a data projector attached to the laptop.

\section{[TABLE 4 ABOUT HERE]}

Over half of those surveyed also reported that they met more regularly in face-to-face mode as a result of having a shared laptop (T4:S3). In this sense the laptop appeared to be a catalyst for group meetings. 
Mode, location and time of access to shared workspace. Table 5 shows access method/location data to the shared workspace for both $3^{\text {rd }}$ and $4^{\text {th }}$ year Civil Engineering project class. From this table it is clear that access to the shared workspace was primarily from within the University $\left(82 \% 3^{\text {rd }}\right.$ year: $83 \% 4^{\text {th }}$ year) rather than from an external site $\left(15 \% 3^{\text {rd }}\right.$ year: $17 \% 4^{\text {th }}$ year $)$. These figures are remarkably consistent across the years and the third year result is also consistent with the survey data (T4:S4). Table 5 also shows that, from within the university, $36 \%$ of third year student access to BSCW was with wireless laptops and $46 \%$ was with other computers in laboratories. Again this finding agrees with the survey response (T4:S5). The login records also proved data on what time of the day students were accessing the shared workspace. Over the duration of the module, access was mainly between 09.00hours and 17.00 hours $(78.7 \%)$ peaking between 12.00 and 14.00 hours. There was a progressive drop in access levels from 17.00 hours onwards. These findings are consistent with the location/access data (Table 5) showing access primarily from within the university.

\section{[TABLE 5 ABOUT HERE]}

Shared workspace versus wireless laptops. In the discussions and in the survey an attempt was made to find out which was considered more valuable to students, the portable laptops or the shared workspace. Perhaps not surprisingly students rated both as equally valuable (T4:S6) given their contention that each supported collaborative working in a different way. However, when asked which they would keep if forced to choose, the laptop or the BSCW website, a majority (59\%) said that they would keep the BSCW website (T4:S7). One plausible interpretation of this is that there are alternatives to the portable laptop within the university (e.g. computer laboratories) whereas it would be difficult for students to replace the functionality of the BSCW website.

Although most students valued the shared laptops, there were mixed views about the optimum number of laptops for project learning. Some students suggested more than one laptop per group while others argued that more laptops might result in less faceto-face meetings.

\section{Discussion}

This study has shown how shared workspaces and wireless laptops might be used to support resource sharing and peer collaboration by students working in project groups. It has also helped identify some important issues in relation to the combined use of these two technologies in project classes.

\section{[TABLE 6 HERE]}

Table 6 maps out and summarises how the implementation of the two technologies helped overcome some typical resource sharing and group collaboration issues. Even though, as Table 7 shows, the application of these technologies was successful there were still some areas of concern. Firstly, not all students felt that the sharing of 
resources across the project groups was successful using the management group folders. Secondly, there were marked differences across project groups in their use of the group workspaces (project group folders) and in the way they organised resources within that workspace (into folders and subfolders). The following sections discuss how to improve resources sharing and the different modes of learner collaboration supported by the two technologies.

\subsection{Improving resource sharing and the role of technology.}

Tolmie (2001) has argued that the effects of computer systems are different depending on the 'contexts of educational and social activity within which they are embedded'. This is consistent with the findings in this study. While most students agreed that the management group folders were an effective way to share resources across project groups their perceptions of assessment requirements and their negative attitudes to resource sharing (the context) limited their actual use these folders. Resolution of this problem does not require changes in the groupware technology itself. Rather it suggests a need for changes in the context of use of that technology (see, Lin \& Hsieh, 2001; Holt, Oliver \& McAvina, 2002). Strategies being considered for future implementations of this project class include better guidance about the use of the management group folders, making more explicit the benefits of group sharing and modifications to the assessment requirements so as to reward the transfer of resources from project folders to the management group folder. Research indicates that these factors might exert a positive influence over students' attitudes to group working and resource sharing (Walker, 2001; Underwood, 2003).

The interplay between technology and educational context is also apparent when we consider how resources were organised and used by project groups. In this study, not all groups fully utilised the project group workspace and most students identified a need for better organisation of resources within that workspace. They also suggested that resources be given a usefulness rating when they were uploaded to the shared workspace. Having students establish the credibility of information in this way has been shown to encourage reflection and deeper learning (Oliver \& Omari, 1999). Hence, while a shared workspace has the potential to help students organise and access resources, effective use of this function is again dependent on the wider context of learning, in this case on students possessing appropriate skills in information organisation and evaluation. Moreover, in addressing this issue, it should be noted that although some students recommended that the teacher provide a structure for the group folders recent research suggests that this might be counterproductive. For example, McDowell (2002) has argued that there is much to be gained by students learning to assume responsibility for this task given that 'accessing and using information and resources is one of the ways in which students begin to act as independent learners' (p254).

In terms of educational design, this study has implications for those interested in applying technology to support learning. First, it shows that the strategy of identifying difficulties in previous implementations of a course and then trying to resolve these by harnessing computer applications has much to commend it. In particular, it increases the likelihood that the technology will embedded and serve a functional role within the educational design (Shaikh \& Macauley, 2001). Secondly, this study shows that even when technology is applied in this way more than one implementation of a 
course might be required before optimal integration is achieved and the full benefits of the technology are realised.

\subsection{Computer applications and modes of collaboration}

An interesting outcome of this investigation was the discovery that the wireless laptops and shared workspaces supported quite different, but complementary, types of collaborative working by students.

The main benefit reported for the wireless laptops was that students could sit down, face-to-face with other group members, at any location within the department, and discuss their project while having easy access to project resources. That students would regard this facility as so valuable was not obvious before this project began and would not have been identified had we not explored the use of shared rather than individual laptops. Around half of the students also reported that the shared laptops encouraged them to meet more frequently in face-to-face mode. These findings have important implications both for education and for the provision of computing resources to students in universities. For example, instead of single workstations there may be a need to increase the provision of portable computers suitable for group work in universities. Alternatively, some of the functionality of the laptops (but perhaps not all of the flexibility) might be made more widely available to students, if instead of single workstations, tables with a fixed computer and group seating were installed in departments or in computer laboratories. This might prove less expensive than issuing laptops as it would spread the costs over larger numbers and a longer time-scale. At the very least, this study suggests that universities might need to reassess what computing facilities will best meet the needs of future students.

In contrast to the laptops, the main benefit of the BSCW workspace was as a shared repository for project resources. Students could access and contribute to the development of shared resources from any location and could observe the progress of their project towards completion. The results showed that use of the shared workspace followed the activity pattern of the project class; i.e. use of the workspace increased significantly over the timeline of the project and peaked as submission deadlines approached for assessed work. In effect, while the laptops served as the 'focus for the coordination for joint activities' in face-to-face mode, the shared workspace acted as a developing 'centre of resources around which group activities were co-ordinated' over time.

In the results, there was also suggestive evidence that some third year project groups might have been using their laptops as a shared repository for working documents. This finding highlights a confounding factor in the design of the present study that requires further research exploration. However, we do not believe that it substantially challenges the argument that these two technologies were supporting different forms of collaboration. At the very least, the high volume of data uploaded into the workspaces indicates that a shared laptop is not a simple substitute for a shared workspace.

What is interesting about the shared workspace in the educational context is its simplicity. BSCW groupware is nothing more than a software shell (or container) for the archiving and updating of project resources. Yet, as this study has shown, this 
simple tool is highly valued by students, even those in an on-campus face-to-face learning environment. The students, in this investigation, studied mostly during daytime (between 09.00 and 17.00 hours) and accessed the shared workspace mainly from within the university network. Nonetheless, this facility was considered so effective by students that they recommended that shared workspaces should be made available to all students to support their study.

\section{Conclusion}

In conclusion, the findings of this investigation are important not only because they show how two technologies might support resource sharing during project learning but also because they help clarify some of the different meanings that the term collaboration might have when used in the context of computer applications. Interestingly, the interpretations of collaboration discovered through this study echo, in some respects, distinctions made by researchers in other contexts. For example, three of Crook's (1994) proposed categories of computer collaboration mentioned in the introduction (with computers, at computers, related to computers) are actually about face-to-face interactions while the fourth (through computers) is about learner interactions at a distance. More relevant is the study by Sikkel et al. (2002) who quoting Robinson (1991) note that 'collaboration involves communication at two levels: exchange of the objects of collaborative work [and] discussion about these objects'. Applied to this investigation, the shared workspace supports the first level collaboration (exchange) while the laptops support the second level (discussion).

\section{References}

Cohen, E.G. (1994). Restructuring the classroom: Conditions for productive small groups. Review of Educational Research, 64(1), 3-35

Cowan, J. (1998). On becoming an innovative university teacher: Reflection in action. SRHE \& Open University Press.

Crook, C (1994). Computers and the Collaborative Experience of Learning. London: Routledge.

deCorte, E. (1988) New perspectives on learning and teaching in higher education. In A. Burgen, Goals and Purposes of Higher Education in the $21^{\text {st }}$ Century. London: Jessica Kingsley Publishers.

Dillenbourg, P. (1999). Introduction: What is meant by collaborative learning? In P. Dillenbourg, Collaborative learning: cognitive and computational approaches. Amsterdam: Pergamon, Elsevier Science.

Holt, R., Oliver, M \& McAvina, C. (2002). Using web-based support for campusbased open learning: lessons from a study in dental public health. Association for Learning Technology Journal, 10(2), 51-62.

Johnson, D.W., Johnson, R.T. \& Smith, K.A. (1998). Cooperative learning returns to college. What evidence is there that it works? Change, 30(4), 26-35. 
Koschmann, T. (1996). Paradigm shifts and instructional technology: An introduction. In T. Koschmann, CSCL: Theory and practice of an emerging paradigm. Mahwah, NJ: Lawrence Erlbaum Associates.

Lin, B. \& Hsieh, C. (2001). Web-based teaching and learner control: a research review. Computers \& Education, 37, 377-386.

McDowell, L. (2002). Electronic information resources in undergraduate education: an exploratory study of opportunities for student learning and independence. British Journal of Educational Technology, 33(3), 255-266.

Oliver, R. \& Omari, A. (1999). Using online technologies to support problem-based learning: Learners' responses and perceptions. Australian Journal of Educational Technology, 15(1), 58-79.

Quin, Z., Johnson, D. W. and Johnson, R T. (1995). Cooperative versus competitive efforts and problem-solving. Review of Educational Research, 65(2), 129-143.

Robinson, M. (1991). Double-level languages and cooperative working. AI and Society, 5, 34-60.

Roschelle, J. \& Teasley, S. D. (1995). The construction of shared knowledge in collaborative problem solving. In C. O'Malley, Computer supported collaborative learning. NY: Springer-Verlag.

Shaikh, A. N. \& Macauley, L. (2001). Integrating groupware technology into the learning environment. Association of Learning Technology Journal, 9(2), 47-63.

Sikkel, K., Gommer, L. \& van der Veen, J. (2002). Using shared workspaces in higher education. Innovations in Education and Training International, 39(1), 26-45.

Slavin, R. (1994). Cooperative learning: theory, research and practice. Boston: Allyn \& Bacon.

Tolmie, A. (2001). Examining learning in relation to the contexts of use of ICT. Journal of Computer Assisted Learning, 17, 235-241.

Underwood, J.D.M. (2003). Student attitudes towards socially acceptable and unacceptable group working practices. British Journal of Psychology, 94, 319-33.

Walker, A. (2001). British psychology students' perceptions of groupwork and peer assessment. Psychology, Learning and Teaching, 1, 28-36. 
FIGURE 1: ACCESS TO THE SHARED WORKSPACE.

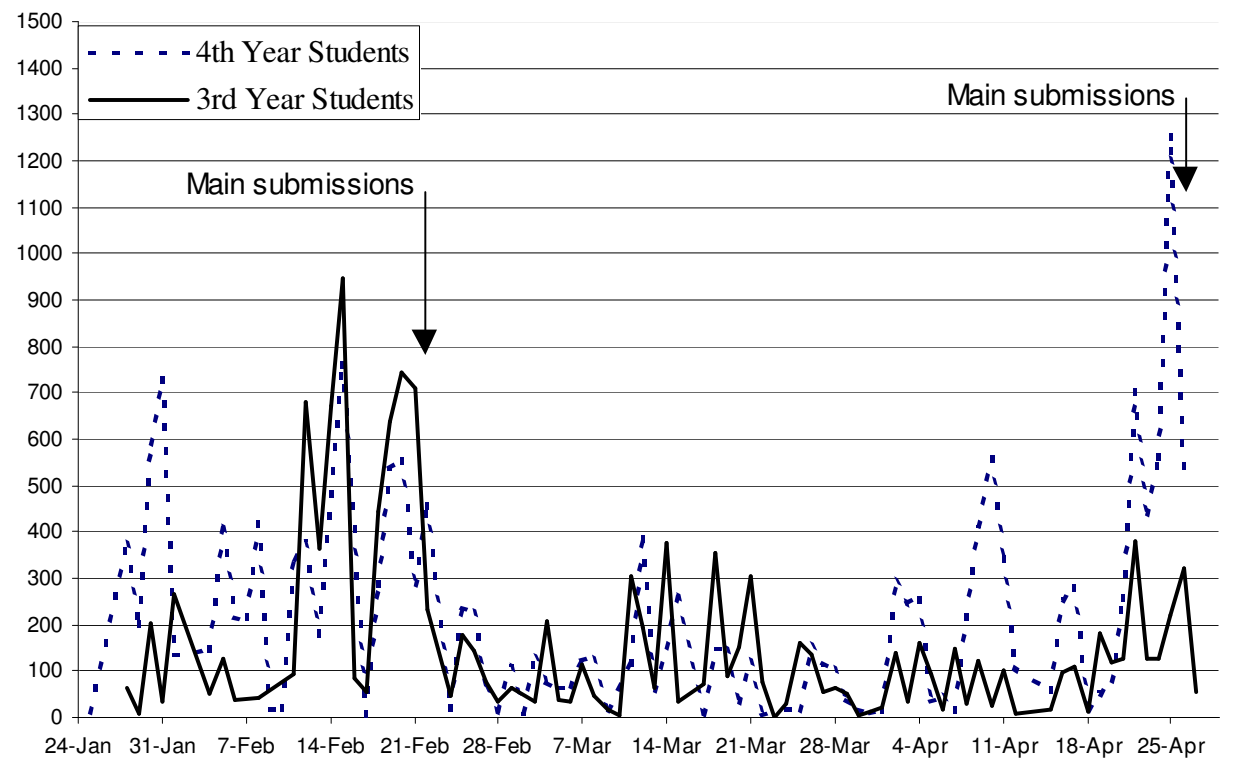


TABLE 1: STUDENT RESPONSES TO THE END OF SEMESTER SURVEY.

\begin{tabular}{|c|c|c|c|}
\hline Number & Survey Statement & $\begin{array}{l}\text { Students } \\
\text { agree } \\
(\%)\end{array}$ & $\begin{array}{l}\text { Students } \\
\text { diasagree } \\
(\%)\end{array}$ \\
\hline 1. & $\begin{array}{l}\text { The BSCW website helped support team working in this } \\
\text { project. }\end{array}$ & 68 & 10 \\
\hline 2. & The BSCW website helps students to share project resources. & 97 & 0 \\
\hline 3. & It is better to share information by email than with BSCW. & 6 & 74 \\
\hline 4. & $\begin{array}{l}\text { The project group folders on the BSCW website make it easy } \\
\text { to track the progress of our project. }\end{array}$ & 56 & 12 \\
\hline 5. & $\begin{array}{l}\text { Seeing information I've tracked down go up on the BSCW site } \\
\text { gives me a sense of satisfaction. }\end{array}$ & 56 & 12 \\
\hline 6. & $\begin{array}{l}\text { Using BSCW helped improve communication within our } \\
\text { project group }\end{array}$ & 29 & 24 \\
\hline 7. & $\begin{array}{l}\text { To make maximum use of project resources online you need a } \\
\text { good structure for the BSCW folders. }\end{array}$ & 97 & 0 \\
\hline 8. & $\begin{array}{l}\text { The teacher should define a structure for the project group } \\
\text { folders on BSCW as was done with the control group folders. }\end{array}$ & 59 & 18 \\
\hline 9. & $\begin{array}{l}\text { It would help if information (e.g. technical reports, references) } \\
\text { uploaded onto the BSCW website were given a usefulness } \\
\text { rating }\end{array}$ & 52 & 18 \\
\hline 10. & I found the BSCW website easy to use & 85 & 6 \\
\hline 11. & $\begin{array}{l}\text { I would have liked more guidance on how to use the BSCW } \\
\text { software. }\end{array}$ & 50 & 26 \\
\hline 12. & Our project group took full advantage of the BSCW facilities & 53 & 15 \\
\hline
\end{tabular}

Note: Figures are derived from responses to a 5 point Likert scale (1-5 with 1=strongly agree and $5=$ strongly disagree). Responses 1 and 2 have been combined to represent the percentage of students 'agreeing' with each statement and similarly responses 4 and 5 represent the percentage 'disagreeing'. The ordering of statements in the table follows the text and was not the order of presentation to students. 
TABLE 2: ANALYSIS OF USAGE OF SHARED WORKSPACE BY EACH GROUP

\begin{tabular}{|c|l|l|c|c|c|}
\hline Group & $\begin{array}{l}\text { No of folders } \\
\text { in root } \\
\text { directory }\end{array}$ & $\begin{array}{l}\text { No of } \\
\text { hierarchical } \\
\text { levels below } \\
\text { root }\end{array}$ & $\begin{array}{l}\text { No of files } \\
\text { containing } \\
\text { project } \\
\text { outcomes }\end{array}$ & $\begin{array}{l}\text { No of files of } \\
\text { minutes of } \\
\text { meetings }\end{array}$ & $\begin{array}{l}\text { Total no of } \\
\text { files }\end{array}$ \\
\hline A & 1 & 0 & 31 & 2 & 50 \\
\hline B & 4 & 2 & 19 & 11 & 39 \\
\hline C & 7 & 2 & 7 & 2 & 23 \\
\hline D & 2 & 1 & 0 & 2 & 16 \\
\hline E & 5 & 1 & 0 & 2 & 4 \\
\hline F & 1 & 0 & 0 & & 4 \\
\hline
\end{tabular}

Notes: No of hierarchical levels below root indicates the number of nested subfolders (a measure of the extent of hierarchy). No of files containing project outcomes is a measure of students' use of the repository for work generated by themselves towards the reports and presentations. No of files of minutes of meetings is a measure of the use of the repository for management information. Total no of files shows overall usage of the repository per group. 
TABLE 3: STUDENT RESPONSES TO THE END OF SEMESTER SURVEY.

\begin{tabular}{|c|c|c|c|}
\hline Number & Survey Statement & $\begin{array}{l}\text { Students } \\
\text { agree } \\
(\%)\end{array}$ & $\begin{array}{l}\text { Students } \\
\text { diasagree } \\
(\%)\end{array}$ \\
\hline 1. & $\begin{array}{l}\text { Sharing of information from the project group to the } \\
\text { management group worked well in this project. }\end{array}$ & 68 & 18 \\
\hline 2. & $\begin{array}{l}\text { The BSCW website is a good way of supporting } \\
\text { communication between the control group and the project } \\
\text { groups. }\end{array}$ & 65 & 6 \\
\hline 3. & Everyone should have access to all areas of the BSCW website & 24 & 53 \\
\hline 4. & $\begin{array}{l}\text { The contribution made by project groups to the management } \\
\text { group folders on the BSCW website should be assessed as part } \\
\text { of the group mark }\end{array}$ & 26 & 47 \\
\hline 5. & $\begin{array}{l}\text { The project group folders were more valuable than the } \\
\text { management group folders }\end{array}$ & 35 & 24 \\
\hline 6. & $\begin{array}{l}\text { If forced to choose, I would rather keep the management group } \\
\text { folder than the project group folders. }\end{array}$ & 29 & 41 \\
\hline 7. & $\begin{array}{l}\text { Every student should have access to a university facility like } \\
\text { BSCW to support their own study. }\end{array}$ & 85 & 3 \\
\hline
\end{tabular}

Note: Figures are derived from responses to a 5 point Likert scale (1-5 with 1=strongly agree and $5=$ strongly disagree). Responses 1 and 2 have been combined to represent the percentage of students 'agreeing' with each statement and similarly responses 4 and 5 represent the percentage 'disagreeing'. The ordering of statements in the table follows the text and was not the order of presentation to students. 
TABLE 4: STUDENT RESPONSES TO THE END OF SEMESTER SURVEY.

\begin{tabular}{|c|c|c|c|}
\hline Number & Survey Statement & $\begin{array}{c}\text { Students } \\
\text { agree } \\
(\%)\end{array}$ & $\begin{array}{c}\text { Students } \\
\text { diasagree } \\
(\%)\end{array}$ \\
\hline 1. & $\begin{array}{l}\text { The shared laptop helped improve communication within our } \\
\text { project group }\end{array}$ & 29 & 26 \\
\hline 2. & $\begin{array}{l}\text { The main educational value of the shared laptop is that you can } \\
\text { work on your project in a small group around a computer }\end{array}$ & 74 & 12 \\
\hline 3. & $\begin{array}{l}\text { As a project group, I think we met more in face-to-face mode } \\
\text { because of the shared laptop }\end{array}$ & 50 & 19 \\
\hline 4. & I mainly accessed BSCW from within the University. & 74 & 6 \\
\hline 5. & I mainly accessed BSCW with the shared laptop. & 41 & 38 \\
\hline 6. & $\begin{array}{l}\text { It is more valuable to have the use of a laptop than to have } \\
\text { access to the BSCW website in this project. }\end{array}$ & 32 & 38 \\
\hline 7. & $\begin{array}{l}\text { If forced to choose, I would rather keep the BSCW website } \\
\text { than a shared laptop for a project of this type. }\end{array}$ & 59 & 26 \\
\hline
\end{tabular}

Note: Figures are derived from responses to a 5 point Likert scale (1-5 with 1=strongly agree and $5=$ strongly disagree). Responses 1 and 2 have been combined to represent the percentage of students 'agreeing' with each statement and similarly responses 4 and 5 represent the percentage 'disagreeing'. The ordering of statements in the table follows the text and was not the order of presentation to students. 
TABLE 5: LOCATION AND MODE OF ACCESS TO THE SHARED WORKSPACES

\begin{tabular}{|l|c|c|}
\hline Mode of Access/location & Third Year Students & Fourth Year Students \\
\hline $\begin{array}{l}\text { Wireless Laptop } \\
\text { (internal access) }\end{array}$ & $36 \%$ & $0 \%$ \\
\hline $\begin{array}{l}\text { University computers } \\
\text { (internal access) }\end{array}$ & $46 \%$ & $83 \%$ \\
\hline ISPs (external access) & $15 \%$ & $17 \%$ \\
\hline Unknown & $3 \%$ & $0 \%$ \\
\hline
\end{tabular}

Note: This table gives relative proportions of access to shared workspace (BSCW) from within and outside the University and with laptops and other computers.

TABLE 6: GROUP COLLABORATION IN AN ENGINEERING PROJECT CLASS: ISSUES AND SOLUTIONS.

\begin{tabular}{|l|l|}
\hline \multicolumn{1}{|c|}{ Issues } & \multicolumn{1}{|c|}{ Solutions } \\
\hline $\begin{array}{l}\text { Organising and sharing large quantities of } \\
\text { information (technical, process, images, reports) }\end{array}$ & $\bullet \begin{array}{l}\text { Project group folders located on the electronic } \\
\text { data repository (shared workspace) }\end{array}$ \\
$\begin{array}{l}\text { Ensuring that all project group members can } \\
\text { easily access project resources. }\end{array}$ & $\bullet \quad \begin{array}{l}\text { Web access from any internet terminal } \\
\text { Radio access with laptops at any location } \\
\text { (table or desk) in the department }\end{array}$ \\
\hline $\begin{array}{l}\text { Students not always being able to attend project } \\
\text { group meetings. }\end{array}$ & $\bullet \begin{array}{l}\text { All information kept in one location so even } \\
\text { if a student can't attend a meeting his/her } \\
\text { work can be accessed by others. }\end{array}$ \\
\hline $\begin{array}{l}\text { Sharing resources across project groups (i.e. } \\
\text { between the project groups and the control group } \\
\text { in this study). }\end{array}$ & $\bullet \begin{array}{l}\text { Management group folders (i.e. class folders) } \\
\text { on BSCW website accessible to all students. } \\
\text { Information uploaded by project group } \\
\text { representative on management group } \\
\text { committee. }\end{array}$ \\
\hline $\begin{array}{l}\text { Students keeping track of the progress being made } \\
\text { by their own project group and course director } \\
\text { keeping track of progress of numerous project } \\
\text { groups. }\end{array}$ & $\bullet \begin{array}{l}\text { Project group folders on BSCW site make it } \\
\text { easier for students and the course director to } \\
\text { check progress }\end{array}$ \\
\hline $\begin{array}{l}\text { Being able to discuss project issues while having } \\
\text { access to all project information and resources. }\end{array}$ & $\bullet \begin{array}{l}\text { Wireless laptops make it easy to access } \\
\text { resources and to sit and discuss the project at } \\
\text { any location within range of base station. }\end{array}$ \\
\hline
\end{tabular}

